\title{
Fresh and Frozen Human Full-thickness Corneal Grafts in Ethiopia
}

\author{
F. O. MUELLER,* L.A.H., D.o. ; P. O’NEILL,* B.SC. ; P. D. TREVOR-ROPER,* M.D., F.R.C.S. \\ H. REITER, $\dagger$ DR.MED. ; R. LUDEK, $\dagger$ DR.MED.
}

Brit. med. F., 1966, 2, 17-20

\begin{abstract}
"The natural origin of man being man himself and thus equal through creation, the only difference lies in the opportunities made available."-Haile Selassie I.
\end{abstract}

Many cases of human blindness are due to corneal opacities, and the sight can be restored only if these are replaced by a clear corneal graft. The donor eye from which the graft is to be cut must be removed within six hours after death, stored at $+4^{\circ}$ C., and used within four days, as after longer intervals the success rate of full-thickness grafts falls off rapidly. It follows that donor corneas, obtained with such difficulty and expense, often fail to find a suitable recipient in the limited time available, and the wastage is enormous.

A satisfactory method for prolonged storage of donor corneas is thus urgently needed. Living cells are not necessary for good functional results of partial-thickness corneal grafts, and material for this purpose can already be stored for months and even years (Fjordbotten, 1965). But the majority of corneal scars penetrate the deeper corneal layers, and call for a fullthickness graft, which will remain clear only if its layer of endothelium is intact and the component cells are alive at the time of transplantation; and methods of long-term preservation of donor eyes for full-thickness keratoplasty at above-zero temperatures have so far failed because the endothelium dies.

Since the reports of Eastcott et al. (1954) and Rycroft (1955) various attempts have been made to preserve the cornea at low temperatures by means of agents, such as glycerol and dimethyl sulphoxide, which have been found to protect these vital endothelial cells against damage when cooling the cornea to, banking it at, and thawing it from below-zero temperatures (Smith, 1965). Both of these subsances were successfully used in in-vitro and in-vivo experiments on rabbits, and later with some success in protecting the human donor cornea against damage (Mueller et al., 1964). In more recent experiments on dog eyes dimethyl sulphoxide alone was used, and, instead of preserving the intact donor eye, only the cornea, together with a rim of sclera, was cooled to, banked at, and later thawed from $-79^{\circ} \mathrm{C}$. and $-196^{\circ} \mathrm{C}$. The experimental work was successful, and a technique has since been established for preserving the anterior segments of human donor eyes at $-196^{\circ} \mathrm{C}$. After preliminary trials fresh and frozen human corneal donor tissue was used in a series of full-thickness keratoplasties in Addis Ababa, and the results are here briefly described. The details of the invitro studies that led to the adoption of the deep-freezing technique we used, as well as the detailed analysis of the individual cases, are being reported elsewhere (O'Neill et al., 1966 ; Mueller et al., 1966).

\section{Local Conditions and Methods}

The series of 46 full-thickness keratoplasties were undertaken at the Ophthalmic Department of the Haile Selassie I Hospital

\footnotetext{
* From the Ophthalmic Research Unit, Westminster Hospital (incorporating the Westminster-Moorfields Eye Bank and the M.R.C. Research Unit, Royal Veterinary College, London).

f From the Eye Department, Haile Selassie I Hospital, Addis Ababa, Ethiopia.
}

of the Haile Selassie Foundation in Addis Ababa. Potentialo patients were assembled, and in the selection of suitables recipients corneal pathology, accurate projection of light, and. intraocular tension were carefully assessed. Most of the blind $\vec{\overrightarrow{ }}$ or near-blind that presented themselves bore dense cornealo scars, and though these were usually vascularized and adherent? to the iris such features were not held to be contraindications, since even a limited improvement in vision was felt to justify operation.

The conditions of the wards were necessarily below the accepted standards for non-emergency surgery. Conjunctival cultures were abandoned because of frequent contamination of the culture plates, and the eyes were cleansed with tetracycline $N$ ointment, twice daily, for the three days before operation. During the period in hospital the patients received tablets of vitamin C (250 mg.) and vitamin-B complex (25 mg.) daily. $\mathscr{8}$ Before the operation the patients' faces were cleaned with soapos and water, the eyelashes were trimmed, and chloramphenicolo eye-drops were instilled hourly for six hours; the patients then walked from the wards to the operating-theatre without any premedication.

The operation was performed under general anaesthesia $\stackrel{\circ}{\odot}$ administered by a locally trained "advanced dresser." The $\vec{F}$ theatre facilities were adequate and the same operating technique 3 was used on all 46 cases. The eye was anchored by sutures? through the superior and inferior rectus, and corneal vascular-0. ization usually called for an excision of a strip of limbal conjunctiva with cautery to the limbal vessels. The donor disc was cut either from the separated anterior segment by punching. it out from the endothelial side on to a concave block of paraffin 3 (Fig. 1) or from the intact eye by trephining it. The hosto cornea was trephined with the same Franceschetti trephine. $\frac{3}{3}$ Anterior synechiae were either separated with a repositor or cut with scissors, and the corneal section was completed with graft scissors. The donor cornea was sutured in place by multiple $N$ interrupted sutures of virgin silk, with a 6-mm. Dello needle. Finally, air was injected into the anterior chamber and tetracycline ointment inserted, together with atropine ointment in $N$ those eyes where the pupillary sphincter was intact; and bothN eyes were padded and bandaged. The eyes were dressed and examined every third day and a tetracycline ointment was normally inserted at each dressing, until the third post-operative week, when topical steroids were added. All patients were given $\cong$ acetazolamide tablets ( $250 \mathrm{mg}$. daily) from 48 hours after the operation until discharge from hospital.

The sutures were removed during the fourth and fifth postoperative weeks under general anaesthesia, except in the few $\frac{\mathbb{Q}}{\circ}$ cases where topical cocaine sufficed.

\section{Donor Material}

Both fresh and deep-frozen $\left(-196^{\circ}\right.$ C.) corneal donor material was used. The fresh material was obtained from the Moorfields-Westminster Eye Bank in London and from the "International Eye Bank" in Colombo, Ceylon; these eyes were transported by air-freight in polystyrene eye-transport 
boxes (Mueller, et al., 1965) and arrived within 48 hours of enucleation. Those that could not be used within a further 36 hours were discarded. Prior to acceptance as suitable material for transplanting, one eye of some pairs was used for a screening test of corneal endothelial viability (O'Neill et al., 1966).

With difficulty some local material, consisting of an excised cornea with scleral rim, was obtained. After the usual criteria had been applied the suitable half-pairs were transplanted within 48 hours of excision.

The frozen material was prepared and banked prior to departure from London in the research unit of the Westminster Hospital Ophthalmic Department at the Royal Veterinary College. It was air-freighted to Addis Ababa in a Linde LR-35 liquid-nitrogen refrigerator. The duration of storage varied between 15 and 37 days.

The material subsequently banked at $-196^{\circ} \mathrm{C}$. was prepared as follows. The anterior segment of a recently enucleated eye

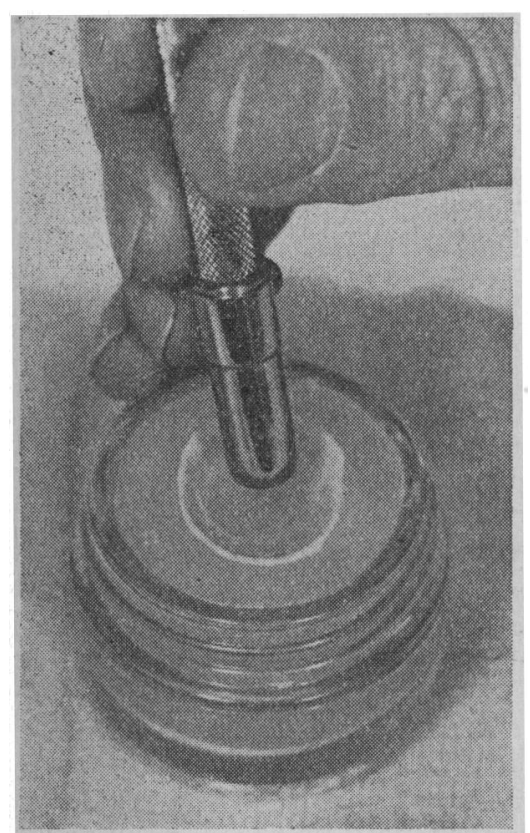

FIg. 1.-Cutting of donor disc from the endothelial side on to the concavity in a paraffin block.

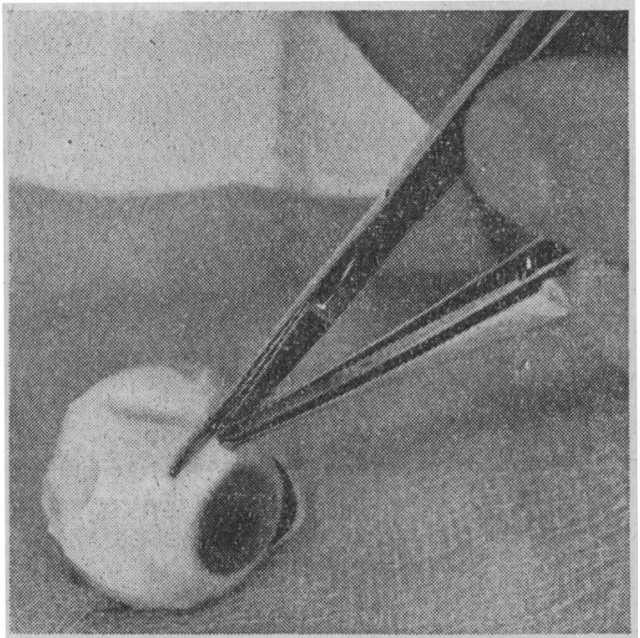

Fig. 2.-Preparation of donor eye for freezing. The cornea with a rim of sclera is dissected from the remainder of the globe. was dissected from the remainder of the globe with scalpel and scissors (Fig. 2). The adherent iris was removed by gentle traction, and the cornea, together with a 3-mm. scleral rim, was immersed in $5 \mathrm{ml}$. of freezing solution at $+4^{\circ} \mathrm{C}$., which contained $14 \%$ (by volume) dimethyl sulphoxide in an aluminium container (Fig. 3). The container was sealed with a polyethylene lid and immersed in a cooling-bath at $+4^{\circ} \mathrm{C}$., then cooled to $-65^{\circ} \mathrm{C}$. at the programmed rate of the solid carbon-dioxide/alcohol cooler before being transferred to the liquid-nitrogen refrigerator for storage.

Immediately before the operation the aluminium container was removed from the bank and its contents were thawed rapidly by immersion in a water-bath at $+55^{\circ} \mathrm{C}$. When all the ice had melted the tissue was transferred to $8 \mathrm{ml}$. of tissueculture medium at $+4^{\circ} \mathrm{C}$., and after two minutes transferred to a further $8 \mathrm{ml}$. of medium, which was allowed to warm slowly to ambient temperature.

\section{Pre-operative Findings}

Of the 46 patients grafted corneal perforation had occurred in 30 , and either single or extensive anterior synechiae were present in all these eyes (Special Plate, Figs. 4, 6, and 8). In 16 patients anterior cortical cataracts were present, and in four

\footnotetext{
${ }^{1}$ Registered Trade Mark Linde Division of Union Carblde Ltd.
}

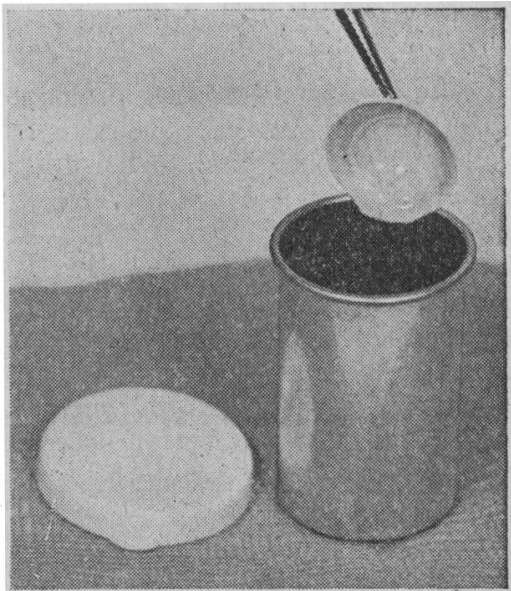

FIG. 3.-Immersion of cornea into aluminium container which holds freezing solution. patients lens, iris, and cornea were adherent to each other (Special Plate, Fig. 7). Five patients were aphakic, and one of them had either lost the lens intracapsularly or the blow causing the injury had dislocated the lens. into the vitreous. All but two fornes showed vascularization, which was in most cases supervascularization of trachoma. Five patients had received surgical treatment for trachomatous entropion, and 17 showed definite trachomatous scarring of the upper tarsal conjunctiva. One patient presented tuberculous skin ulcers around his only eye, with a painful destruction of the nose and adjacent tissues. Of female ; in 17 patients the fellow eye 30 were male and 16 were aged below 20 , and 20 were between 20 and 30 ; the youngest patient was aged 7 and the oldest 57.

\section{Results from Fresh Donor Corneas}

All fresh donor eyes subsequently used for full-thickness keratoplasty showed either fine generalized oedema with dense pavement opacities in the corneal stroma or the corneas were

diffusely opaque, and this even before the cutting of the donor discs. Towards the end of the operation the stroma of the transplants had either cleared slightly or even increased. The epithelium of the graft did not float off, and its removal was not attempted. All grafts showed during the second and third post-operative weeks a great reduction of the oedema, but the transplants of a larger diameter cleared more slowly. After the removal of sutures they cleared completely (Special Plate, Fig. 5) or became again more oedematous. Superficial vascularization around the sutures was visible at the beginning of the fourth week but regressed after suture removal and could not be detected after a further week.

The second and all following months were without complications in those 16 grafts which had been virtually clear at the time of removal of sutures. One of these clear grafts, however, became oedematous 12 weeks after the operation because of secondary glaucoma; this graft remained oedematous until the twenty-third week, when an iris inclusion was performed, and within a week the transplant had regained its clarity, leaving only a fine paracentral opacity in Bowman's membrane. One graft developed early a narrow sickle-shaped post-graft membrane which did not affect the clarity of the transplant.

Three grafts were clear over their greater extent at the end of the twelfth, and two at the end of the twenty-fifth post-operative week, and anterior chamber details could be seen with ease; a 
section of the two grafts remained oedematous at the host-graft junction, and these were therefore counted as only partially successful.

Four grafts failed. The oedema of the stroma in these grafts increased after removal of sutures, became stationary during the third post-operative month, and regressed during the later months. All these four grafts still show a diffuse oedema with some, but minimal, vascularization of the stroma.

Thus 16 grafts were successful six months after the operation, two were clear in the greater part, and four failed (Table I). A further five grafts were observed only three months, and two of these were clear, whereas one was partially successful. The results are given in Table II.

TABLB I.-Results of the First Series-From October 1965

\begin{tabular}{|c|c|c|c|c|c|c|c|c|c|c|c|c|c|c|c|c|}
\hline \multirow{3}{*}{ 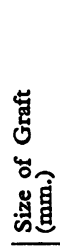 } & \multicolumn{8}{|c|}{ Fresh Material } & \multicolumn{7}{|c|}{ Frozen Material } & \multirow[b]{3}{*}{ 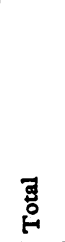 } \\
\hline & \multicolumn{4}{|c|}{3 months } & \multicolumn{4}{|c|}{6 months } & \multicolumn{4}{|c|}{3 months } & \multicolumn{3}{|c|}{6 months } & \\
\hline & $\begin{array}{l}8 \\
0 \\
0 \\
\vdots \\
\end{array}$ & J & 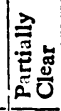 & 总 & उँ & 层 & 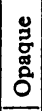 & 莒 & $\begin{array}{l}0 \\
4 \\
0 \\
0 \\
z \\
\end{array}$ & है & 氞 & 总 & $\frac{8}{0}$ & 焉 & 苐 & \\
\hline $\begin{array}{r}5 \\
6 \\
7 \\
8 \\
10\end{array}$ & $\begin{array}{r}2 \\
3 \\
12 \\
4 \\
1\end{array}$ & $\begin{array}{l}1 \\
3 \\
9 \\
2\end{array}$ & $\begin{array}{l}2 \\
1\end{array}$ & $\begin{array}{l}1 \\
1 \\
1 \\
1\end{array}$ & $\begin{array}{l}1 \\
3 \\
9 \\
3\end{array}$ & 2 & $\begin{array}{l}1 \\
1 \\
1 \\
1\end{array}$ & $\begin{array}{l}1 / 2 \\
3 / 3 \\
9 / 12 \\
3 / 4 \\
0 / 1\end{array}$ & $\begin{array}{l}3 \\
4 \\
1\end{array}$ & $\begin{array}{l}3 \\
2 \\
1\end{array}$ & 2 & & $\begin{array}{l}3 \\
3 \\
1\end{array}$ & 7 & $\begin{array}{l}3 / 3 \\
3 / 4 \\
1 / 1\end{array}$ & $\begin{array}{c}1 / 2 \\
6 / 6 \\
12 / 16 \\
4 / 5 \\
0 / 1\end{array}$ \\
\hline
\end{tabular}

TABLE II.-Results of the Second Series-From February 1966

\begin{tabular}{|c|c|c|c|c|c|c|c|c|c|c|c|}
\hline \multirow[b]{2}{*}{$\begin{array}{c}\text { Size } \\
\text { of } \\
\text { Graft }\end{array}$} & \multicolumn{5}{|c|}{ Fresh Material 3 Months } & \multicolumn{5}{|c|}{ Frozen Material 3 Months } & \multirow[b]{2}{*}{ Total } \\
\hline & \begin{tabular}{|c|} 
No. \\
of \\
Cases
\end{tabular} & Clear & \begin{tabular}{|c|} 
Par- \\
tially \\
Clear
\end{tabular} & Opaque & Result & $\mid \begin{array}{c}\text { No. } \\
\text { of } \\
\text { Cases }\end{array}$ & Clear & $\mid \begin{array}{c}\text { Par- } \\
\text { tially } \\
\text { Clear }\end{array}$ & Opaque & Result & \\
\hline $\begin{array}{r}6 \\
7 \\
8 \\
10\end{array}$ & $\begin{array}{l}2 \\
2 \\
1\end{array}$ & $\begin{array}{l}2 \\
1 \\
1\end{array}$ & 1 & & $\begin{array}{l}2 / 2 \\
1 / 2 \\
1 / 1\end{array}$ & $\begin{array}{l}2 \\
8 \\
1\end{array}$ & $\begin{array}{l}2 \\
7\end{array}$ & $\begin{array}{l}1 \\
1\end{array}$ & & $\begin{array}{l}2 / 2 \\
7 / 8 \\
0 / 1\end{array}$ & $\begin{array}{l}4 / 4 \\
7 / 8 \\
1 / 3 \\
1 / 1\end{array}$ \\
\hline
\end{tabular}

\section{Results from Deep-frozen Donor Corneas}

The epithelium of the donor was lost either while punchingout the disc or during suturing of the graft. The stroma was clear, and remained so until the end of the operation, except at the margin of the disc, where forceps had repeatedly gripped the edge during suturing. During the first two post-operative weeks the grafts still remained clear, but then fine oedema appeared in the deep layers of the stroma. At the time of removal of sutures 10 of the 19 grafts showed only a fine haze, and were clear a few days later; the remaining five cleared within the next three weeks after the removal of sutures (Special Plate, Figs. 7 and 9). One graft, clear until the eleventh week after the operation, developed secondary glaucoma; 11 weeks later an iris-inclusion operation was performed, and within a few days the frozen transplant had regained clarity.

Three grafts became oedematous after the second post-operative week, but started to clear at the beginning of the second post-operative month. At the end of the second post-operative month anterior chamber details could be seen and the grafts cleared rapidly, but some oedema remained in the periphery of the transplant, and persisted in one observed two months, and in two that were observed for three months, one graft failed. Seven of the eight grafts examined after six months and 8 of the 11 observed for three months were clear, and three were clear over two-thirds of the transplant six and three months after operation. The results are shown in Tables I and II.

\section{Visual Results}

Because of amblyopia, nystagmus, and cataracts the visual results varied greatly. Twenty of the 46 patients obtained uncorrected vision of $6 / 24$ and better, six a visual acuity of
$6 / 60$ to $6 / 36$, and 18 improved from " hand movements" to "counting fingers." Two patients lost part of their preoperative vision because of very oedematous grafts.

\section{Discussion}

The selection of the patient was primarily governed by the prognosis and the prospect of maintaining clarity of the graft for long periods, because local conditions make continuous observation and treatment difficult. Apart from three patients, neither refraction nor prescription of glasses was attempted, as the patients can rarely afford the expense of spectacles and their way of life does not demand a very high visual acuity. The surgical technique in all 46 cases was similar, and the preand post-operative treatment did not vary, since the extent of the damage to the corneas that we grafted made assessment of the results difficult enough without the introduction of other variants. A full assessment of the patients' general condition was not practicable, and tuberculosis (which has a high incidence in Addis Ababa) could not be excluded. Hence, early and intensive treatment with steroids, whether systemically or subconjunctivally or topically, was omitted; the operated eyes may have been more injected in the absence of intensive steroid treatment, but this inflammatory reaction did not seem to affect the grafts, and the vascularization was as transient as is usual when steroids are given. The lack of cooperation of the patients was considerable, but the results demonstrate that adverse conditions are no real barrier to keratoplasty. None of the grafted eyes developed intraocular infection, and none developed anterior synechiae as a result of a leak in the hostgraft junction.

Many of the fresh donor eyes were unsatisfactory, and 25 of the 52 received were either used for viability tests or discarded as unsuitable. However, one of the purposes of the trial in Addis Ababa was to examine the possibility of using fresh donor eyes for full-thickness corneal grafts in faraway countries, and we believe that fresh eyes can in fact be used, though at a fair price-in both labour and finance.

The use of glycerol, which had previously been found to be superior for the protection of the donor epithelium at low temperatures, was abandoned, as the survival of epithelial cells after transplanting is unimportant ; and the replacement of the aqueous with the medium containing dimethyl sulphoxide became unnecessary when it was decided simply to suspend the cornea with its sclera rim in this protective medium. Liquid nitrogen was used for the storage of the donor material because refrigerators for the storage of tissues at this temperature are readily available. It is of interest that in the seven frankly trachomatous corneas neither fresh nor frozen grafts became vascularized, and, particularly, that many frozen full-thickness grafts did not behave differently from grafts of the available fresh donor material, because they were clear at, and remained clear after, the removal of sutures (Special Plate, Figs. 5, 7, and 9).

\section{Summary}

A series of 46 full-thickness corneal grafts is described. These were performed in Addis Ababa, fresh and deep-frozen donor corneas being used; in spite of difficult conditions, and very unpromising recipient eyes, the results were gratifying, yielding 33 clear grafts at three and six months' follow-up. Eighteen out of the 27 fresh eyes and 15 out of the 19 frozen corneas gave good results.

Fifty-two fresh donor eyes were obtained, some locally and others flown in from London and Ceylon, but 15 of these had to be discarded because they were unsuitable. Ten were used for viability tests. All the frozen donor eyes which arrived in Addis Ababa from London were used for full-thickness keratoplasty. 
An improved method of banking the donor material at low temperature is described, entailing the immersion of the cornea with an attached rim of sclera in medium containing dimethyl sulphoxide. The storage temperature is that of liquid nitrogen $\left(-196^{\circ}\right.$ C. $)$ instead of that of solid carbon dioxide $\left(-79^{\circ} \mathrm{C}.\right)$, as formerly used.

Though the results with deep-frozen donor material were superior to those with fresh material, many further trials will be needed before this apparent superiority of frozen material can be established. But it can reasonably be concluded that deepfreezing provides a satisfactory method of preservation, and should eliminate the present wastage of this valuable donor material.

The work was jointly supported by the "Action for the Crippled Child" Fund, London, and by the Haile Selassie I Foundation, Addis Ababa ; to these, and to the Medical Research Council, who supported all our preliminary investigations, we are greatly indebted. We must also thank Professor E. C. Amoroso and Professor G. Formston, of the Royal Veterinary College, from whose premises we operated; and the Governors of Westminster Hospital and Moorfields Eye Hospital, who provided us with the services of the Westminster-Moorfields Eye Bank. Many individual members of these hospitals gave us constant assistance, particularly Mr. Baker and his staff in the Pharmaceutical Department and Dr. Hansell's Medical Illustration Department at Westminster.

We would like to acknowledge more personally the assistance given by Ato Melesse Nazir, by Sister Macdesse Gizaw and Sister Kenya Gizaw at the Haile Selassie I Hospital ; Dr. Paulos Quana, ophthalmologist to the Menelik II Hospital in Addis Ababa ; and Dr. Hudson Silva, who provided so many fresh eyes from the Ceylon Eye Donation Society's Eye Bank in Colombo.

We are also grateful to Union Carbide Linde Division, the Metal Box Co., and Rayner \& Keeler Ltd., who provided us with necessary equipment.

REFERENCES

Eastcott, H. H. G., Cross, A. G., Leigh, A. G., and North, D. P. (1954). Lancet, 1, 237.

Fiordbotten, A. L. (1965). The Cornea. Butterworths, London.

Mueller, F. Casey, T. A., and Trevor-Roper, P. D. (1964). Brit. med. $\mathcal{f}_{\text {., }} 2,473$.

(1965), Ibid., 2, 267.

O'Neill, P., Muelle, F. O., and Trevor-Roper, P. D. (1966). In prepara-

tion. Rycroft, B. W. (1955). Corneal Grafts. Butterworths, London.

Smith, A. U. (1965). In The Cornea, p. 384. Butterworths, London. Smith, A. U. (1965). In The Cornea, p.

\title{
Histopathological Changes in the Foetal and Infantile Inner Ear Caused by Maternal Rubella*
}

\author{
I. FRIEDMANN, $\dagger$ M.D., D.C.P., F.C.PATH. ; M. I. WRIGHT, $\ddagger$ M.R.C.S., L.R.C.P., D.C.P., M.C.PATH.
}

\author{
[With Special Plate]
}

Brit. med. F., 1966, 2, 20-23

The special vulnerability of the eye, ear, and heart of the developing foetus in maternal rubella during the first trimester of pregnancy is now well recognized (Gregg, 1941; Swan, Tostevin, Moore, Mayo, and Black, 1943).

The incidence of deafness in maternal rubella, however, cannot be exactly determined, as there is some variation in the figures given by various authors (Manson, Logan, and Loy, 1960 ; Barr and Lundstrom, 1961 ; Rendle-Short, 1964 ; Fraser, 1964 ; Lamy, 1964 ; and others).

Sheridan (1964), on the basis of one of the best prospective inquiries by Manson et al. (1960) for the Ministry of Health, concluded that major abnormalities, mainly of the eye, ear, and heart, occurred in $15 \%$ of children of mothers who had rubella in the first weeks of pregnancy. Rendle-Short (1964) suggested that deafness might occur in $50 \%$ of affected children, but may be only partial. These inquiries have shown up very clearly the importance of rubella in early pregnancy as a cause of congenital deafness and the need for long-term followup and periodic full reassessment of children known to be at risk from maternal rubella during the first 16 weeks of pregnancy, as recommended by Fisch (1955).

It has become even more important since modern virological and serological methods have furnished additional evidence of the profound teratogenic role of clinical as well as subclinical rubella infections. These are bound to affect our thinking on the part played by the rubella virus in the causation of profound

\footnotetext{
* This paper is based on lectures given by one of us (I. F.) at the Departments of Otolaryngology of Iowa University, the Mount Sinai Hospital, New York, Yale University, and the Massachusetts Eye and Ear Hospital.

† Professor of Pathology, University of London.

I Senior Lecturer in Clinical Pathology, University of London.
}

childhood deafness (Alford, Neva, and Weller, 1964 ; Dudgeon, Butler, and Plotkin, 1964 ; Plotkin, Oskin, Hartnett, Hervada, Friedman, and Gowing, 1965 ; Lambert, Stern, and Wellstead, 1965).

In contrast with the rapid progress of the epidemiology and virology of rubella, new knowledge of the histopathology of rubella deafness has remained fragmentary, owing to the relatively small number of available temporal-bone specimens. The first case was described by Carruthers in 1945. Schall, Lurie, and Kelemen (1951) and Kelemen and Gotlib (1959) studied the temporal bones of embryos removed from mothers who had suffered from rubella during the first three months of pregnancy. There was extensive haemorrhage in the inner ear; this finding was incriminated as the main cause of arrested development of the auditory apparatus.

Nager (1952) described the temporal bones from three children ; in two these showed definite malformations, and in the third they showed only partial damage of the inner ear.

Gray (1959) studied the inner ear of a $53-\mathrm{mm}$. foetus whose mother developed rubella on the 37th day of pregnancy ( 51 days after L.M.P.). The principal lesion seemed to be a lysis of the epithelium of the organ of Corti leading to disappearance of the sensory cells.

The clearest description of the histopathological changes was given by Lindsay, Carruthers, Hemenway, and Harrison (1953), who examined the inner ears of four children exposed to maternal rubella in the early months of pregnancy. It is interesting to note that only one of the children who had suffered from severe bilateral deafness and died at the age of 5 years showed bilateral cochleo-saccular degeneration.

The findings were interpreted as the direct effect of the rubella virus upon the vascular stria, affecting the endolymph and the 
F. O. MUELLER AND OTHERS: FRESH AND FROZEN HUMAN CORNEAL GRAFTS

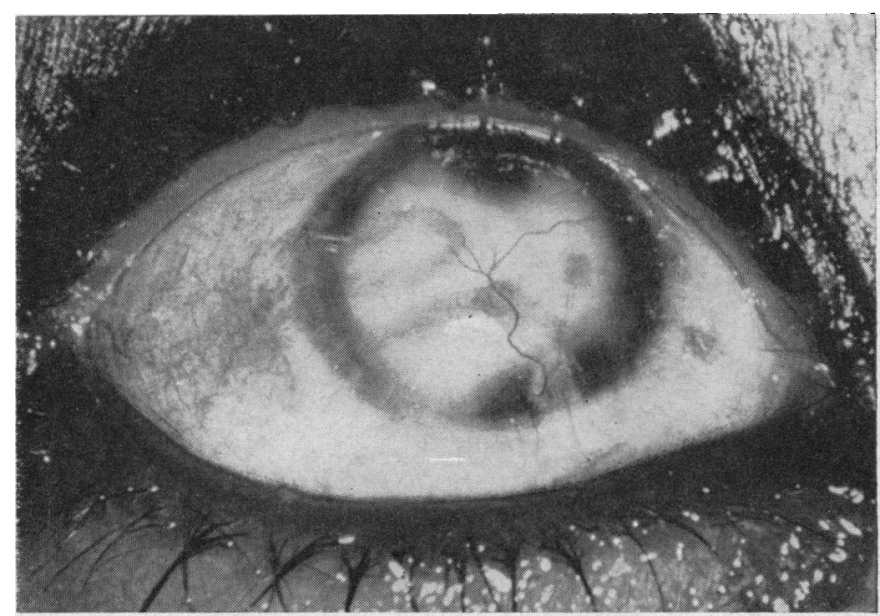

FIG. 4.-Case 3. Extensive corneal scar with perforation before fullthickness corneal graft.

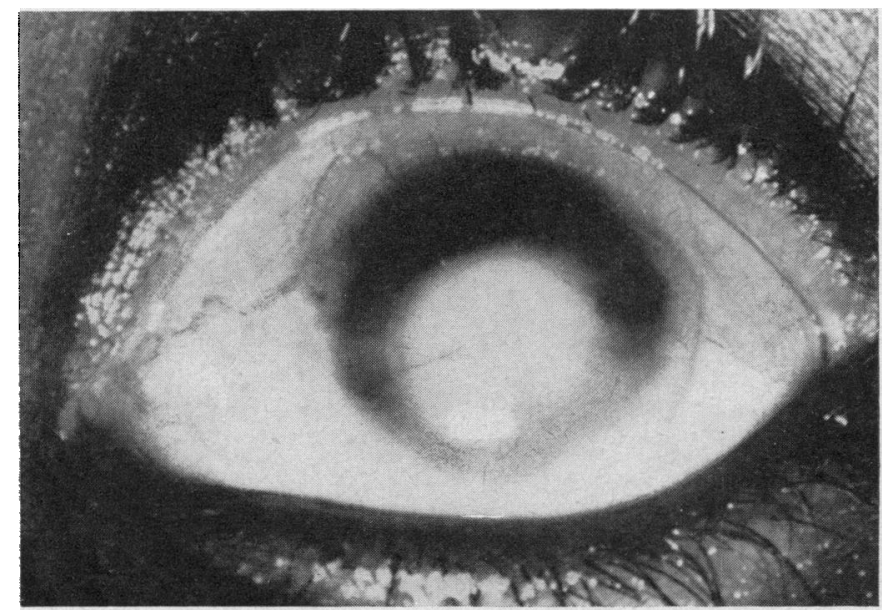

Fig. 6.-Case 12. Diffuse opacification of cornea with central scar and perforation.

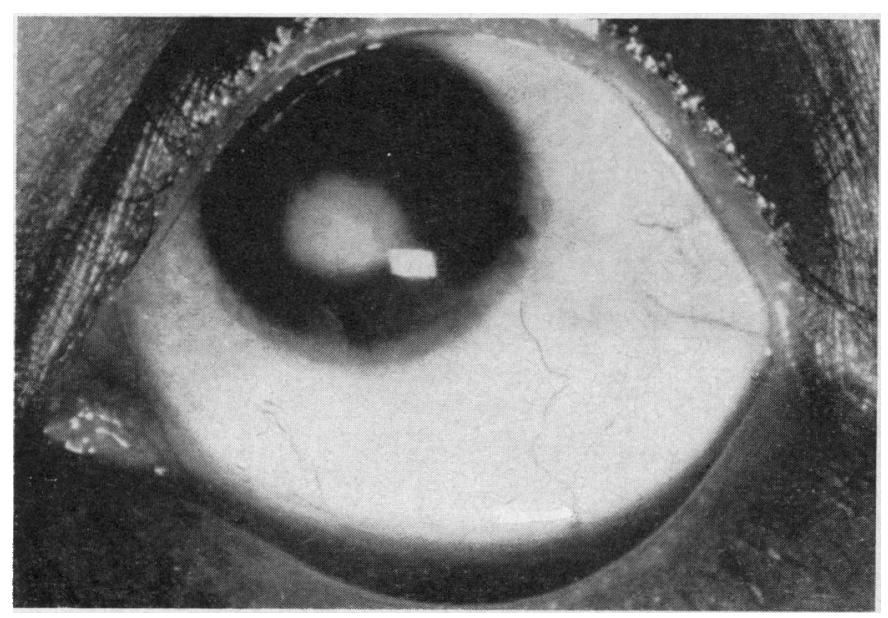

FIG. 8.-Case 15. Paracentral corneal scar with perforation.

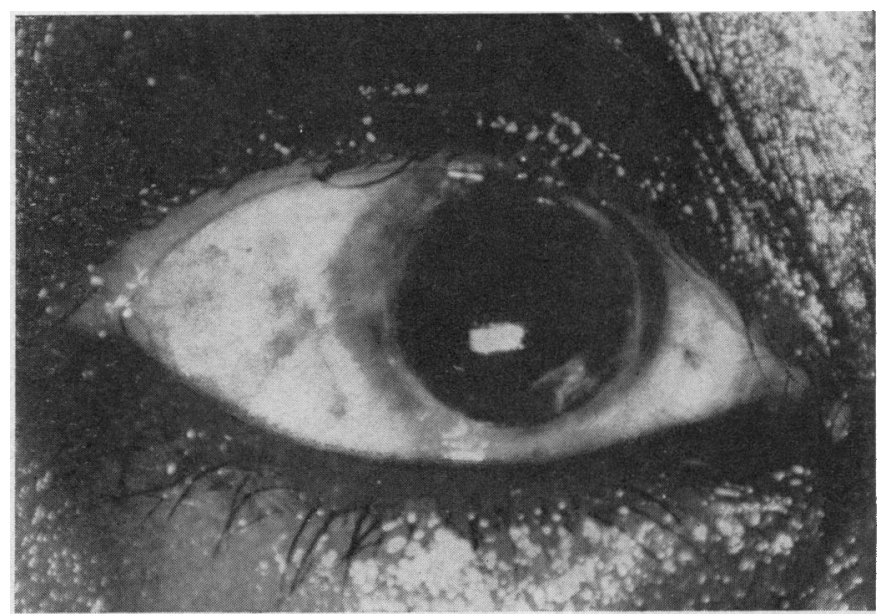

Fig. 5.-Case 3. 8-mm. full-thickness graft. Fresh donor material, 36 days after operation.

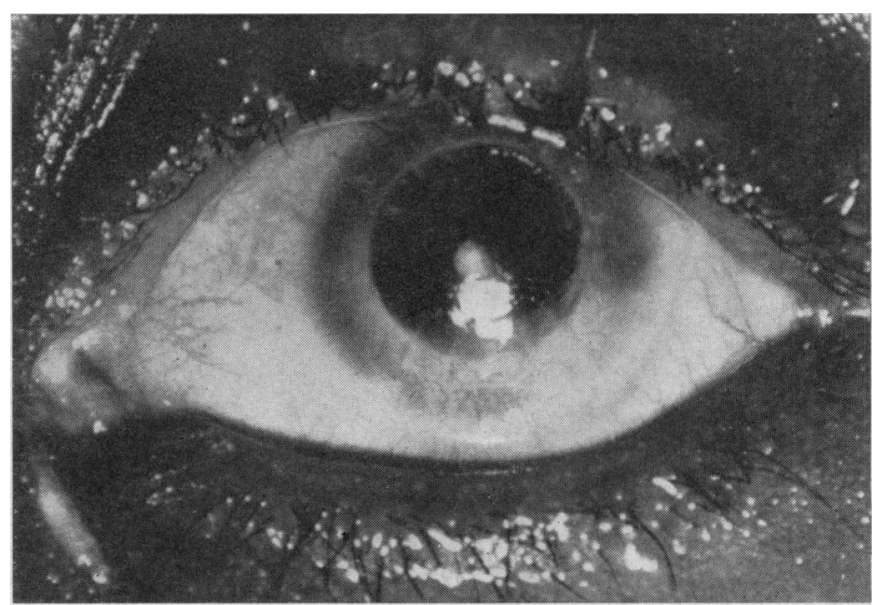

Fig. 7.-Case 12. 7-mm. full-thickness graft with material banked at $-196^{\circ}$ C. for 31 days, 35 days after operation. Notice anterior cortical cataract.

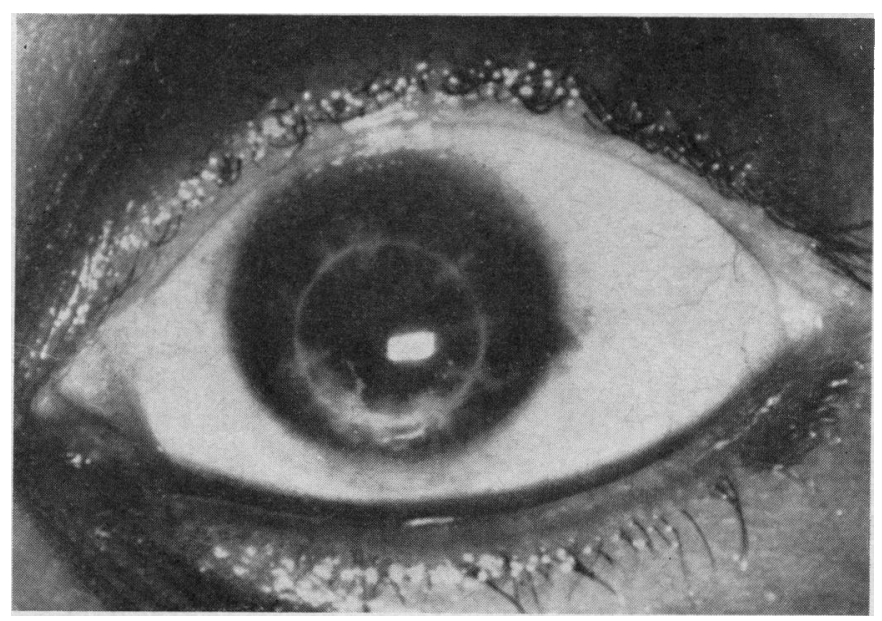

Fig. 9.-Case 15. 6-mm. full-thickness graft with material that had been banked for 34 days at $-196^{\circ}$ C., 30 days after operation.

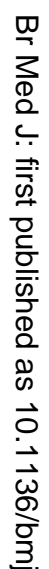
iv G $\stackrel{+}{ \pm}$ 윽

$\stackrel{N}{\complement}$



9

กั

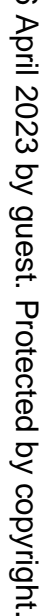

